Brit. J. Ophthal. (1961) 45, 550.

CASE NOTES

\title{
ANEURYSM OF THE ORBITAL PART OF THE OPHTHALMIC ARTERY*
}

\author{
BY \\ A. MORTADA \\ Department of Ophthalmology, Faculty of Medicine, University of Cairo, Egypt
}

DUKE-ELDER (1952) stated that orbital aneurysms of the ophthalmic artery were very rare and that several of the reports lacked anatomical verification. Such cases were described by Guthrie (1823), Carron du Villards (1838), Passavant (1866), Dempsey (1886), Ritter (1887), de Vincentiis (1892), de Schweinitz and Holloway (1908), and Vail and Oliver (1914).

Heimburger, Oberhill, McGarry, and Bucy (1949) reviewed the literature as regards intra-orbital aneurysms, and gave a short summary of six cases in which the diagnosis seemed reasonably sound. They reported an aneurysmal dilatation of the lacrimal artery removed by the transcranial route. Without arteriography, it seems unlikely that the diagnosis of orbital aneurysm can be established without operation. Angiograms were taken by Huber (1951) and Kinley and Leighninger (1952).

Weakening of the arterial wall may be due to a developmental malformation, trauma, arteriosclerotic degeneration, or a septic embolus usually from bacterial endocarditis. Moore (1925) described a mycotic ophthalmic aneurysm which caused complete rupture of the optic nerve.

The ophthalmic artery aneurysms described were rarely of the saccular variety, but rather consisted of a dilatation of the artery over a long segment. Pfingst (1936), who concluded that up to that date no case of saccular aneurysm of the ophthalmic artery had been proved, described a unilateral fusiform distension of the ophthalmic artery. Sanford, Craig, and Wagener (1935) reported a bilateral fusiform aneurysm of the ophthalmic artery verified by operation. There is no particular histological feature by which an arterial dilatation of this kind can be distinguished from a fusiform aneurysm.

Walsh (1957) summarized the signs of aneurysm of the ophthalmic artery as: proptosis, optic atrophy or papilloedema, field defects, diplopia, and limitation of ocular movements, saying that "it seems unlikely that ocular pulsation is present; certainly in most of the instances pulsation signifies arteriovenous aneurysm". Sverdlick and Veppo (1950) described nonpulsating exophthalmos associated with fusiform dilatation of the

* Received for publication October 24, 1960. 
ophthalmic artery. In a few of the cases described, including my own case, there was a pulsating exophthalmos.

Sugar and Meyer (1940) described arteriovenous orbital aneurysm and divided cases of pulsating exophthalmos into the true and pseudo-pulsating types. Cases of true pulsation are due to carotid cavernous fistulous aneurysm, intra-orbital aneurysm, and (rarely) arteriovenous aneurysm between the internal carotid and the jugular vein. Pseudo-pulsating exophthalmos-not of aneurysmal origin -includes orbital angioma, orbital meningocele, and defects in the orbital roof.

Involvement of the $3 \mathrm{rd}$, 4th, 5th, and 6 th nerves, oedema of the lids and conjunctiva, the arterialized pulsating angular vein, and the presence of a bruit suggest a cavernous-carotid communication. This is the commonest cause of pulsating exophthalmos. In a fistulous aneurysm, compression of the arterial vessel in the neck leads to a sharp slowing of the pulse (Branhan's sign) and elevation of the oxygen content of the venous blood of the regional veins (Brown, 1929). Horton and Ziegler (1930) differentiated between an arteriovenous communication and an orbital aneurysm by this method. In orbital aneurysm the bruit is localized and less marked. Terry and Mysel (1934) reported pulsating exophthalmos caused by a communicating aneurysm between the internal carotid and the jugular vein at the entrance of the carotid canal.

An arteriovenous aneurysm in the orbit is rare. Lansdown (1875) and Terry and Fred (1938) reported aneurysmal communications between the angular vein and the infratrochlear branch of the ophthalmic artery. A circoid aneurysm of the orbit giving rise to pulsating exophthalmos is rare (Frothingham, 1877; Kümmell, 1918; Vail, 1949).

An aneurysm of the internal maxillary artery filling the maxillary antrum and invading the orbit causing pulsating exophthalmos was reported by de Takats (1932).

Differential diagnosis of the type of aneurysm in question is easily cleared up by an angiograph (Picchini, 1935; Taptas, 1949).

The causes of pseudo-pulsating exophthalmos are: retrobulbar angioendothelioma (Röttgen, 1950); defects in the orbital roof as in von Recklinghausen's disease transmitting cerebral pulsations to the eye (Lewald, 1933); or hydrocephalic brain (Verbiest, 1953); traumatic herniation of cerebrum into the orbit (Baron, 1937); orbital meningocele; mucocele of the sphenoid sinus (O'Shea, 1932); and thrombotic obliteration of the cavernous sinus (Lagrange, 1904).

Orbital aneurysms may be treated by ligature of the corresponding common carotid artery. They may be approached directly by an anterior orbital, Krönlein, or transcranial approach, and in suitable cases may be excised entirely or alternatively ligated. 


\section{Case Report}

A 51-year-old woman (Fig. 1) complained of headache, and pulsating exophthalmos of the left eye of 7 months' duration. The condition began with buzzing noises and pain in the left eye.

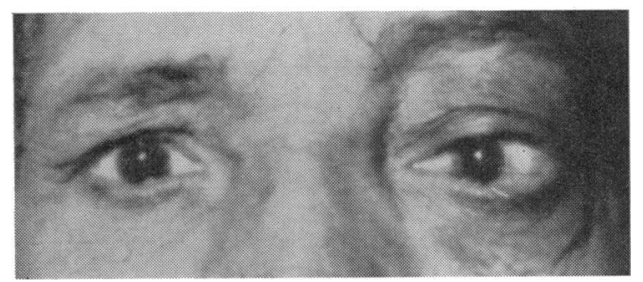

Fug. 1.-Left pulsating exophthalmos due to aneurysmal dilatation of orbital part of ophthalmic artery.

The patient denied any history of trauma, abortion, or rheumatic pain. She had one son aged 15 ,years. The family and past histories were without significance. Her general health was perfect. There were no visible angiomatous lesions. The body temperature, and pulse and respiration rates were normal. The heart was normal, showing no evidence of infective endocarditis. The blood pressure was 160 systolic and 90 diastolic. Sensations over the face and forehead were intact. Examination for septic foci was negative. The angular vein was not tortuous or pulsating.

Right Eye.-Normal externally. Immature cataract prevented fundus examination. Visual acuity $1 / 60$.

Left Eye.-The lids and conjunctiva showed no oedema or dilated tortuous vessels. There was slight ptosis due to partial 3rd nerve paralysis, and convergent squint due to 6th nerve paralysis. Corneal sensations were intact. The pupil was normal in size and reactions. There was limitation of outward movement but the other ocular movements were normal. The fundus showed arteriosclerotic changes of the retinal vessels. The visual acuity was $6 / 18$, with no error of refraction.

The exophthalmos measured $20 \mathrm{~mm}$. Hertel (that of the right eye being $16 \mathrm{~mm}$.). The eye was not tender. The eyeball was pulsating, but this was not visible, only palpable. A cystic pulsating cyst was present at the inner upper side of the orbit behind the angular process of the frontal bone, transmitting pulsations to the eyeball and lids synchronous with each arterial systole. Pulsations in the cyst gave to the examiner's fingers a sensation of the thrust of passing blood. The pulsating cyst was not adherent to the upper lid, and it evacuated on pressure. A bruit could be heard with the stethoscope over the left eye and cystic orbital swelling. The pulsations and bruit ceased on pressing the left common carotid artery in the neck.

The blood Wassermann reaction and tuberculin tests were negative. Total and differential blood counts, faeces, and urine examinations were normal.

$X$ rays of the skull were normal. The left orbit was not wider than the right. Sphenoidal fissures, optic canals, sella turcica, clinoid processes, and nasal sinuses were normal. There were no abnormal calcified shadows in the skull or orbits.

In the lateral left arteriogram, the left internal carotid artery and its siphon showed no dilatation. The left middle and anterior cerebral arteries and the intracranial part of the ophthalmic artery were normal. There was aneurysmal dilatation, tortuosity, and delayed emptying of the orbital part of the left ophthalmic artery along its whole course. Its diameter was approximately three times that of the internal carotid. There was no intracranial or orbital arteriovenous communication (Fig. 2).

In an antero-posterior arteriogram, the aneurysmal dilated tortuous orbital part of the ophthalmic artery was seen as a rounded opacity present in the upper part of the orbital cavity (Fig. 3). An oblique skull arteriogram showed similar findings (Fig. 4). 


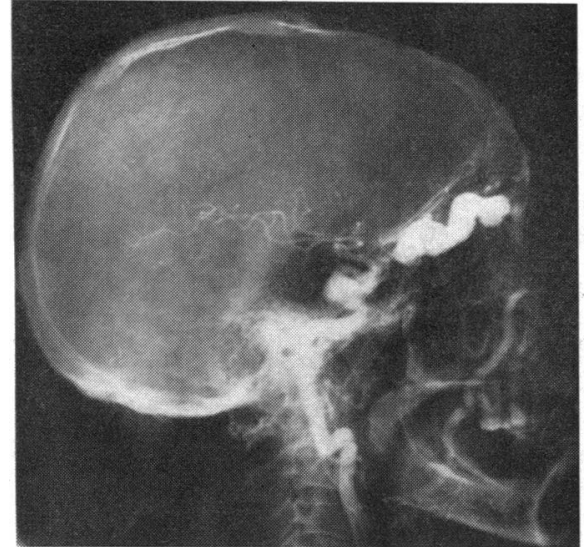

FIG. 2.-Arteriogram, lateral view, showing aneurysmal dilatation and tortuosity of orbital part of ophthalmic artery.

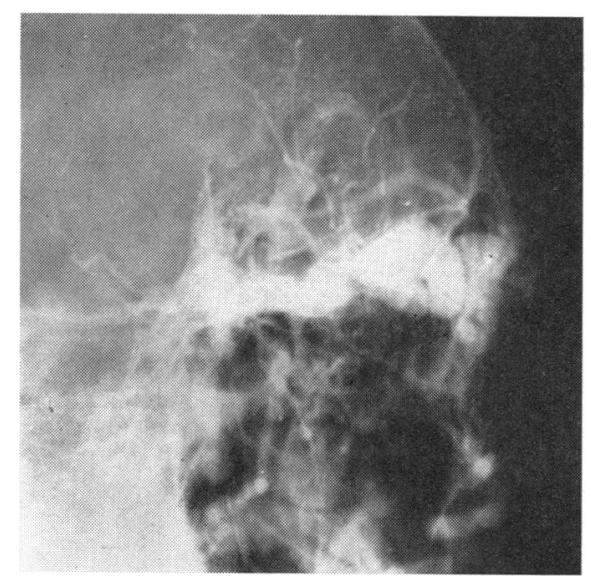

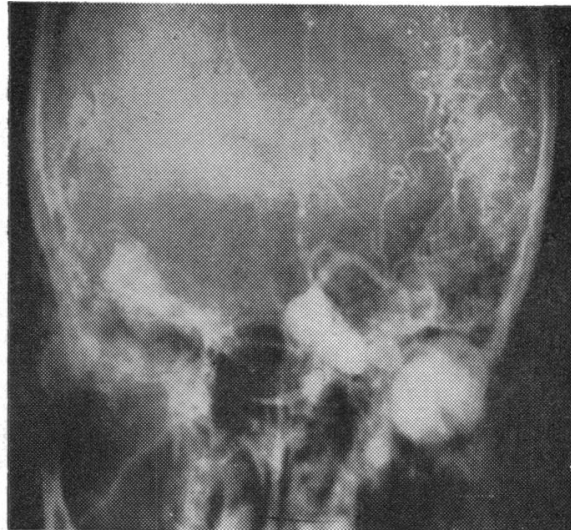

FIG. 3.-Arteriogram, antero-posterior view, showing aneurysm of orbital part of ophthalmic artery seen as a rounded opacity.

FIG. 4.-Arteriogram, oblique view, showing opacity in left orbit due to ophthalmic artery aneurysm.

Therapy.-The left common carotid artery was compressed against Chassaignac's tubercle on the sixth cervical vertebra five times daily beginning with one and increasing to 15 minutes. There was no cerebral embarrassment such as dizziness, weakness, or numbness of the contralateral side of the body or affection of vision. Ligature of the left common carotid artery cured the pulsating exophthalmos. The aneurysm was no longer palpable in the orbit.

\section{Summary}

Pulsating exophthalmos is usually due to a carotid cavernous or orbital arteriovenous communication. A very rare case of pulsating exophthalmos due to a non-fistulous aneurysm of the orbital part of the ophthalmic artery is recorded. The condition began at the age of 51 with absence of history of trauma, syphilis, septic foci, or infective endocarditis. Evidence of retinal arteriosclerosis suggested the probable cause of the aneurysm. Arteriograms 
of ophthalmic artery aneurysms are rare in the literature. Lateral, anteroposterior and oblique skull arteriograms showed that the aneurysm was not saccular and not fistulous, but a tortuous diffuse dilatation of the whole course of the orbital part of the ophthalmic artery. It was about three times the diameter of the internal carotid. The case was cured by ligature of the common carotid. This is the first case of ophthalmic artery aneurysm recorded from Egypt.

\section{REFERENCES}

BARON, P. (1937). Brit. J. Surg., 25, 459.

Brown, G. E. (1929). Arch. Surg., 18, 807.

CARRON DU VILLARDS, C. J. F. (1838). "Guide pratique pour l'étude et le traitement des maladies des yeux", vol. 1, p. 484, Paris.

DEMPSEY, A. (1886). Brit. med. J., $2,541$.

De Schweinitz, G. E., and Holloway, T. B. (1908). "Pulsating Exophthalmos". Saunders, Philadelphia.

DukE-Elder, S. (1952). "Text-book of Ophthalmology”, vol. 5, p. 5405. Kimpton, London.

Frothingham, G. E. (1877). Amer. J. med. Sci., 73, 97.

Guthrie, G. (1823). "Lectures on the Operative Surgery of the Eye". Burgess and Hill, London.

Horton, B. T., and Ziegler, L. H. (1930). Proc. Mayo Clin., 5, 178.

Heimburger, R. F., Oberhill, H. R., McGarry, H. I., and Bucy, P. C. (1949). Arch. Ophthal. (Chicago), 42, 1 .

Huber, A. (1951). Bull. Soc. franç. Ophtal., 64, 347.

KINLEY, G. J., and LeIGHNINGER, D. S. (1952). J. Neurosurg., 9, 544.

KÜMMELL, R. (1918). Arch. Augenheilk., 83, 261.

Lagrange, F. (1904). "Traité des tumeurs de l'oeil", vol. 2, p. 552. Steinheil, Paris.

LANSDOWN, F. P. (1875). Brit. med. J., 1, 736, 846.

LEWALD, L. T. (1933). Amer. J. Roentgenol., 30, 756.

MOORE, R. F. (1925). "Medical Ophthalmology", 2nd ed., p. 92. Churchill, London.

O'SHEA, H. V. (1932). Lancet, 1, 1253.

Passavant (1866). In L: DeWecker, "Traité théorique et pratique des maladies des yeux", 2nd ed., vol. 1, p. 733. Delahaye, Paris.

Picchini, G. (1935). G. clin. Med., 16, 1210.

Pfingst, A. O. (1936). Arch. Ophthal. (Chicago), 16, 829.

RITTER (1887). Jb. Ges. Natur. Heilk., p. 61.

RöttGen, P. (1950). Klin. Mbl. Augenheilk., 116, 256.

SANFord, H. S., Craig, W. McK., and Wagener, H. P. (1935). Proc. Mayo Clin., 10, 721.

Sugar, H. S., and MeYer, S. J. (1940). Arch. Ophthal. (Chicago), 23, 1288.

SVERDLICK, J., and VePPo, A. (1950). Arch. Oftal. B. Aires, 25, 472.

DE TAKats, G. (1932). Arch. Ophthal. (Chicago), 8, 259.

TAPTAS, J. N. (1949). Bull. Soc. Ophtal. Fr., 1, 449.

Terry, T. L., and Fred, G. B. (1938). Arch. Ophthal. (Chicago), 19, 90.

W and MYSEL, P. (1934). J. Amer. med. Ass., 103, 1036.

VAIL, D. (1949). Postgrad. Med., 5, 439. and Oliver, J. C. (1914). Lancet-Clinic, 111, 644.

Verbiest, H. (1953). J. Neurosurg., 10, 264.

DE VINCENTIIS, C. (1892). Atti roy. Accad. med. chir. Napoli, 46, 452.

WALSH, F. B. (1957). "Clinical Neuro-Ophthalmology", 2nd ed., p. 821. Williams and Wilkins, Baltimore. 